\title{
Drosophila Nociceptive Sensitization Requires BMP Signaling via the Canonical SMAD Pathway
}

\author{
Taylor L. Follansbee, ${ }^{1}$ Kayla J. Gjelsvik, ${ }^{1}$ Courtney L. Brann, ${ }^{1}$ Aidan L. McParland, ${ }^{1}{ }^{\mathbb{C}}$ Colin A. Longhurst, ${ }^{2}$ \\ Michael J. Galko, ${ }^{3}$ and ${ }^{\circledR}$ Geoffrey K. Ganter ${ }^{1}$ \\ ${ }^{1}$ Department of Biology, College of Arts and Sciences, University of New England, Biddeford, Maine 04005, 2Department of Biostatistics and Medical \\ Informatics, University of Wisconsin-Madison, Madison, Wisconsin 53792, and ${ }^{3}$ Department of Genetics, Division of Basic Science Research, University of \\ Texas M.D. Anderson Cancer Center, Houston, Texas 77030
}

Nociceptive sensitization is a common feature in chronic pain, but its basic cellular mechanisms are only partially understood. The present study used the Drosophila melanogaster model system and a candidate gene approach to identify novel components required for modulation of an injury-induced nociceptive sensitization pathway presumably downstream of Hedgehog. This study demonstrates that RNAi silencing of a member of the Bone Morphogenetic Protein (BMP) signaling pathway, Decapentaplegic (Dpp), specifically in the Class IV multidendritic nociceptive neuron, significantly attenuated ultraviolet injury-induced sensitization. Furthermore, overexpression of Dpp in Class IV neurons was sufficient to induce thermal hypersensitivity in the absence of injury. The requirement of various BMP receptors and members of the SMAD signal transduction pathway in nociceptive sensitization was also demonstrated. The effects of BMP signaling were shown to be largely specific to the sensitization pathway and not associated with changes in nociception in the absence of injury or with changes in dendritic morphology. Thus, the results demonstrate that Dpp and its pathway play a crucial and novel role in nociceptive sensitization. Because the BMP family is so strongly conserved between vertebrates and invertebrates, it seems likely that the components analyzed in this study represent potential therapeutic targets for the treatment of chronic pain in humans.

Key words: injury; pain

\section{Significance Statement}

This report provides a genetic analysis of primary nociceptive neuron mechanisms that promote sensitization in response to injury. Drosophila melanogaster larvae whose primary nociceptive neurons were reduced in levels of specific components of the BMP signaling pathway, were injured and then tested for nocifensive responses to a normally subnoxious stimulus. Results suggest that nociceptive neurons use the BMP2/4 ligand, along with identified receptors and intracellular transducers to transition to a sensitized state. These findings are consistent with the observation that BMP receptor hyperactivation correlates with bone abnormalities and pain sensitization in fibrodysplasia ossificans progressiva (Kitterman et al., 2012). Because nociceptive sensitization is associated with chronic pain, these findings indicate that human BMP pathway components may represent targets for novel pain-relieving drugs.

\section{Introduction}

Chronic pain, perpetuated by the neuroplastic process of nociceptive sensitization, affects millions of people worldwide (Gaskin

\footnotetext{
Received Nov. 8, 2016; revised June 24, 2017; accepted July 27, 2017.

Author contributions: T.L.F., K.J.G., C.L.B., A.L.M., M.J.G., and G.K.G. designed research; T.L.F., K.J.G., C.L.B., and A.L.M. performed research; T.L.F., K.J.G., C.L.B., A.L.M., C.L., M.J.G., and G.K.G. analyzed data; T.L.F., K.J.G., C.L.B., A.L.M., C.L., M.J.G., and G.K.G. wrote the paper.

This work was supported by National Institutes of Health/National Institute of General Medical Sciences Award 1P20GM103643-01A1 to lan Meng, National Institutes of Health/National Institute of Neurological Disorders and Stroke Award 1R15NS095195- 01 to G.K.G., Peter Caradonna, and the University of New England Microscope Core Facility supported by National Science Foundation 0116398 and 1125672. Stocks obtained from the Bloomington Drosophila Stock Center (National Institutes of Health P400D018537) were used in this study. We thank Daniel Cox for assistance with morphometric approaches and for fly lines; lan Meng for critical comments on the manuscript; Volkhard Lindner for the p-mad antibody; and Rema Weston, Michael Esty, and Cody Barba for technical support.

The authors declare no competing financial interests.
}

and Richard, 2012). Sensitization in response to tissue damage can produce a reduction in nociceptive thresholds that in some cases can outlast the initial injury. A more detailed knowledge of the pathways that lead to nociceptive neuron sensitization may allow for the identification of novel targets for the treatment of chronic pain. It has been estimated that $75 \%$ of known human disease genes have relatives in the Drosophila genome (Reiter et al., 2001), allowing the genetically tractable fly to serve as a relevant model for human ailments, including neurological disorders (Pandey and Nichols, 2011; Wangler et al., 2015).

Correspondence should be addressed to Dr. Geoffrey K Ganter, University of New England, 11 Hills Beach Road Biddeford, ME 04005. E-mail: gganter@une.edu.

DOI:10.1523/JNEUROSCI.3458-16.2017

Copyright $\odot 2017$ the authors $\quad 0270-6474 / 17 / 378524-10 \$ 15.00 / 0$ 


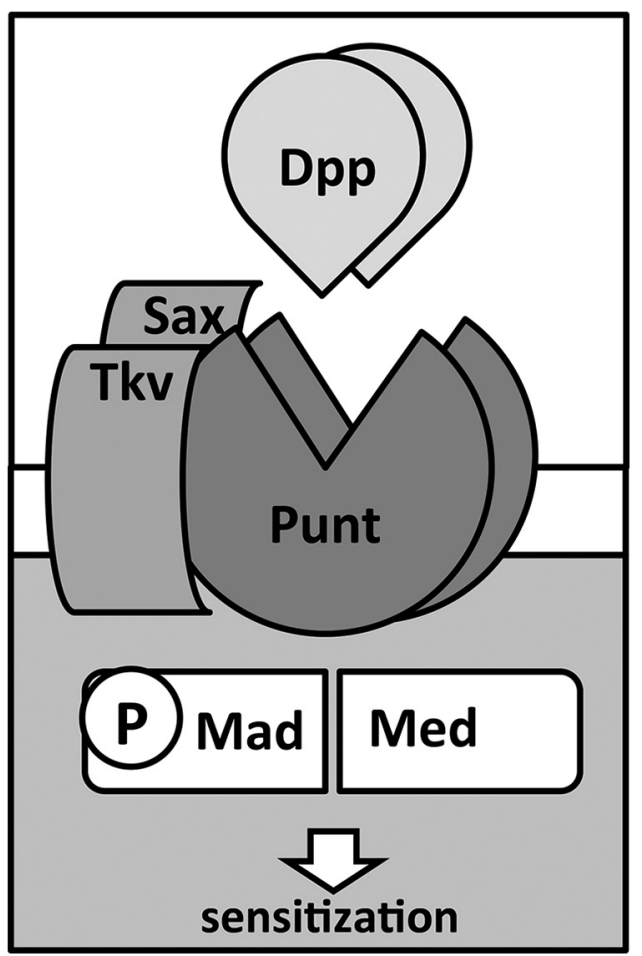

Figure 1. Model illustrating the BMP signaling components found to be necessary for pain sensitization in Drosophila larval nociceptive neurons. Dpp (orthologous to BMP2/4) ligand binds to its primary Type II receptor, Punt (orthologous to the Type II TGF $\beta$ receptor). Subsequent activation of Type I receptors Tkv (orthologous to ALK3/6) and Sax (orthologous to ALK1/2) leads to phosphorylation of the SMAD transducer Mad (cofounder of SMAD family), which then binds Med (orthologous to SMAD4).

Previous studies have used ultraviolet (UV)-induced tissue damage to sensitize nociceptive neurons in Drosophila larvae. A defined dose of UV irradiation was delivered to anesthetized animals; and $24 \mathrm{~h}$ later, wild-type animals demonstrated an increase in sensitivity to a light touch with a thermal probe at a normally subthreshold temperature, referred to as thermal allodynia (Babcock et al., 2009). Using this model, three pathways have been identified: TNF- $\alpha$ (Babcock et al., 2009; Jo et al., 2017), Hedgehog (Hh) (Babcock et al., 2011), and tachykinin (TK) (Im et al., 2015), which are required for communication among the injured epidermis, the underlying nociceptive neurons, and the CNS to bring about the observed thermal allodynia. The Drosophila Bone Morphogenetic Protein (BMP) Decapentaplegic (Dpp) lies downstream of $\mathrm{Hh}$, yet its involvement in the sensitization of nociceptive neurons remains unknown.

Dpp, a fly ortholog of mammalian BMP2 (Ozkaynak et al., 1990) and BMP4 (Jones et al., 1991), is a member of the TGF- $\beta$ superfamily of signaling proteins (Padgett et al., 1993) and, as depicted in Figure 1, binds to receptors (Massagué and Like, 1985 ) in the serine/threonine kinase family (Lin et al., 1992). Dpp's primary receptor Punt (Put) (Letsou et al., 1995), orthologous to Type II TGF- $\beta$ receptors, activates Thick Veins (Tkv) (Ruberte et al., 1995) and Saxophone (Sax) (Xie et al., 1994; Nellen et al., 1994), both orthologous to Type I TGF- $\beta$ receptors. In turn, the Type I receptors modify the intracellular transducer Mothers Against Decapentaplegic (Mad) (Sekelsky et al., 1995) by phosphorylation and subsequent translocation to the nucleus (Newfeld et al., 1997) as a complex with Medea (Med) (Wisotzkey et al., 1998). Mad and Med are members of the SMAD group named after the small Caenorhabditis elegans SMA mutant
(Brenner, 1974) and Drosophila melanogaster Mad. As examples of the strong conservation between mammalian and Drosophila BMP components, prior studies have shown that Dpp can induce endochondral bone formation in mice (Sampath et al., 1993), and human BMP4 DNA sequences inserted into the fly genome rescue Dpp-deficient larvae to normal development (Padgett et al., 1993).

In the Drosophila larva, four classes of primary afferent neurons, referred to as dendritic arborization neurons, innervate the body wall. Classification is based on increasing levels of dendritic arborization (Grueber et al., 2012). Class IV dendritic arborization neurons, referred to as nociceptive neurons in this report, have the most elaborate epidermal arbors of naked dendrites and respond to noxious mechanical and thermal (heat) stimulation (Tracey et al., 2003). These neurons express nocisensitive ion channels, such as Painless, a Transient Receptor Potential (TRP) channel orthologous to mammalian TRPA1 (Tracey et al., 2003); Pickpocket (Ppk), a degenerin-like mechanosensory channel (Adams et al., 1998); the Drosophila dTRPA1, sensitive to electrophiles (Kang et al., 2012) and heat (Neely et al., 2011); and the mechanosensor Piezo (Kim et al., 2012).

In this study, cell-specific RNAi suppression of BMP pathway components in nociceptive neurons was used to demonstrate that BMP signaling via a canonical pathway is required for UVinjury induced allodynia. Because of the high degree of functional conservation between mammalian and Drosophila BMP components, components of the human BMP pathway may represent new leads with potential therapeutic value.

\section{Materials and Methods}

Fly stocks and genetics. Flies were maintained in 6 oz stock bottles on sucrose-cornmeal-yeast medium at a temperature of $25^{\circ} \mathrm{C}$ with a humidity of 50\%-60\%. Stock bottles were kept in Percival Scientific Incubators with a $12 \mathrm{~h}$ light $/ 12 \mathrm{~h}$ dark cycle. The arbitrary dawn time for the incubators was set to 9:00 A.M. The GAL4/UAS system was used to drive expression of UAS-inverted repeat (IR) RNAi transgenes targeting specific genes of interest. The driver in all experiments was Ppk1.9-Gal4, which expresses GAL4 specifically in the Class IV multidendritic nociceptive neurons (Ainsley et al., 2003). The Ppk1.9-Gal4 line used also contained a Ppk-GFP element, allowing direct visualization of morphology of these neurons (generous gift from Daniel Cox). All other flies were obtained from the Bloomington Drosophila Stock Center (BDSC; Bloomington, Indiana). The transgenic UAS-RNAi lines used, featuring IR construction for RNAi suppression, were as follows: $D P p^{I R}$ (BDSC \#35214, 25782), Put ${ }^{I R}$ (BDSC \#35195, 27514), Tkv $v^{I R}$ (BDSC \#35166, 35653), Sax $^{I R}$ (BDSC \#55865, 36131), Mad ${ }^{I R}$ (BDSC \#35648, 43183), and $\mathrm{Med}^{I R}$ (BDSC \#31928, 43961). Additionally, a UAS-Dpp line (BDSC \#1486) (Ward and Berg, 2005) was used to overexpress Dpp. Animals were included without regard to sex.

UV injury. A method of UV induced allodynia was applied (Babcock et al., 2009). Third instar larvae were collected $4 \mathrm{~d}$ after egg laying, rinsed, and anesthetized with diethyl ether. Anesthetized larvae were gently adhered dorsal side up to double-sided tape on a microscope slide and were subjected to $12-15 \mathrm{~mJ} / \mathrm{cm}^{2}$ of UV light delivered in $\sim 2-5 \mathrm{~s}$ in a Spectronics Spectrolinker XL-1000 ultraviolet crosslinker. The larvae were then placed in a small vial containing $\sim 1 \mathrm{ml}$ of sucrose-cornmeal-yeast media and allowed to recover for $24 \mathrm{~h}$ before assays were performed.

Thermal nociception assay. To test nociceptive behavior, the larvae were assayed with a thermal probe (Pro-Dev Engineering) $24 \mathrm{~h}$ after UV exposure. The probe tip was gently applied to the dorsal side of the larvae and held on abdominal segments $2-4$ for a maximum of $20 \mathrm{~s}$. To test for allodynia, the larvae were subjected to $41^{\circ} \mathrm{C}$, the highest temperature that did not elicit a behavioral response in our hands (Fig. 2). The larval response consisted of a nocifensive $360^{\circ}$ lateral rolling that larvae only exhibit in response to a noxious stimulus (Tracey et al., 2003). The latency for response was recorded and categorized as follows: fast was $0-6$ 


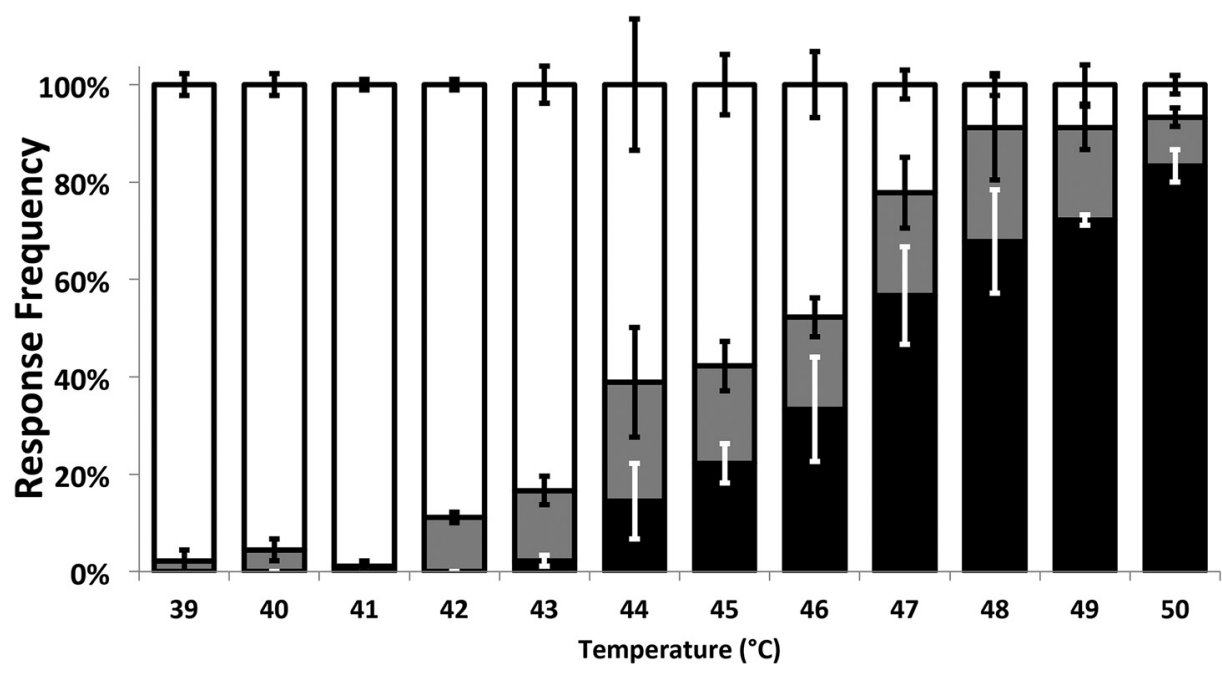

Figure 2. Thermonociception response of wild-type animals. The percentage of wild-type $\left(w^{1118}\right)$ animals that responded to the thermal probe increased with increasing probe temperature from $39^{\circ} \mathrm{C}$ to $50^{\circ} \mathrm{C} ; 42^{\circ} \mathrm{C}$ was the lowest temperature for which there was a statistically significant proportion of animals responding; therefore, in this study, $41^{\circ} \mathrm{C}$, the highest innocuous temperature, was selected for use in subsequent allodynia testing. Larvae responding with a nocifensive roll were classified as fast ( $<6 \mathrm{~s}$, black area), slow ( $6-20 \mathrm{~s}$, gray area), or nonresponders if they did not respond within $20 \mathrm{~s}$ (white area). Whiskers indicate SEM of at least three groups of larvae. Distributions were compared using Fisher's exact test. $n=90$ for each group.

$\mathrm{s}$ (indicated by black regions on graphs), slow was 6-20 s (gray), and no response if the $20 \mathrm{~s}$ cutoff was reached (white). To assay normal nociceptive function (see Fig. 10), larvae were tested at $45^{\circ} \mathrm{C}$, and the time to respond was recorded and presented as average response latency. The probe operator was blinded to the UV treatment and genotype, and all groups contained a sample size of at least 90 animals.

Quantification of dendritic morphology. Class IV multidendritic neurons were analyzed for total dendritic length and number of dendritic branches (Iyer et al., 2013). Third instar larvae were anesthetized with $\mathrm{CO}_{2}$ and placed on a microscope slide with a halocarbon-ether mixture (2:1). Larvae were imaged with a Leica SP5 confocal laser microscope using a $20 \times$ objective. ddaC neurons, the most dorsal pair of Class IV nociceptive neurons (Grueber et al., 2012), were imaged from abdominal segments $4-6$, and $z$ stacks were taken with a $0.76 \mu \mathrm{m}$ step size to capture the whole dendritic field. Images were taken with a resolution of $1024 \times$ 1024. Images were skeletonized and analyzed for parameters of dendritic length and dendritic branching in the open source image-processing package Fiji (https://imagej.net/Fiji).

Immunohistochemistry conditions and imaging. Third instar larvae bearing Ppk-GFP to specifically visualize the nociceptive neurons were filleted longitudinally by incision along the ventral midline without anesthesia, and all tissues internal to the muscular body wall were removed. The body wall was pinned flat on a silicone (Sylgard) surface, fixed 20 min in fresh $4 \%$ PFA in PBS, washed in PBS $0.1 \%$ Triton X-100 (PBS-T), and blocked overnight at $4{ }^{\circ} \mathrm{C}$ with $5 \%$ normal goat serum in PBS-T. The intensity of BMP receptor and transducer immunoreactivity were compared in control and UAS-RNAi-expressing animals. Primary antibodies to Put (Abcam 14680, 1:100) were incubated $1 \mathrm{~h}$ at room temperature, then overnight at $4^{\circ} \mathrm{C}$ washed in PBS-T and visualized with fluorescently conjugated secondary antibodies (AlexaFluor-568, Abcam) at 1:500, incubated for $2 \mathrm{~h}$ at room temperature followed by washing with PBS-T. Suitable antibodies to Med, Sax, and Tkv were not available. The Mad antibody was raised against mammalian p-Smad1/5/8 (generous gift from Volkhard Lindner, Maine Medical Center Research Institute) and used at 1:500. Animals were analyzed $0,2,4,8,16$, and $24 \mathrm{~h}$ after UV injury. For each BMP component, eight larvae were analyzed. The ddaC nociceptive neurons in abdominal segments $4-6$ were identified by eGFP fluorescence and studied for a total of 10-12 cells per component, and analyzed by confocal microscopy. Images were collected using a Leica SP5 Scanning Confocal Microscope using a $40 \times$ oil objective. All images were resolved at $1024 \times 1024$, and a $Z$ stack was collected to ensure that the entire cell was analyzed. The $Z$ stacks were collapsed into maximum projections, and the relative intensity of staining was analyzed using Fiji (https://imagej.net/Fiji). For immunohistochemistry results,

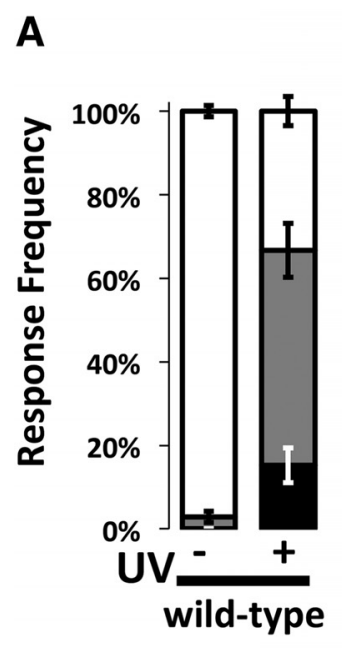

B

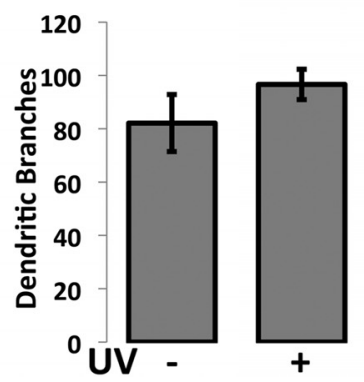

Figure 3. UV injury results in allodynia without altering gross dendriticmorphology of nociceptive neurons. $\boldsymbol{A}$, UV injury leads to allodynia. At $24 \mathrm{~h}$ after UV exposure, there was a statistically significan increase in the number of animals that responded to a previously innocuous stimulus, $41^{\circ} \mathrm{C}$. Response latencies were recorded in seconds and categorized as follows: fast ( $<6 \mathrm{~s}$, black area), slow (6-20s, gray area), or nonresponders if they did not respond within $20 \mathrm{~s}$ (white area). $n=90-117$, and distributions were compared using MLR analysis. Whiskers indicate SEM of at least three groups of larvae. $\boldsymbol{B}, \boldsymbol{C}$, Dendritic morphology of nociceptive neurons of normal animals (Ppk1.9-Gal4 $>y^{7} v^{7}$ ) exposed to UV injury is similar to that of uninjured controls. The total number of dendritic branches $(\boldsymbol{B})$ and total dendritic length (C) were compared in neurons visualized via Ppk-GFP. Analysis of larvae not subjected to UV injury (left) and those subjected to UV injury (right) shows no significant changes in morphology. Skeletons were constructed in Fiji, and total dendritic length and the total numbers of branches were calculated. Data were analyzed by Welch's $t$ test. $n=18$ for each group. ${ }^{* * *} p<0.001$. 

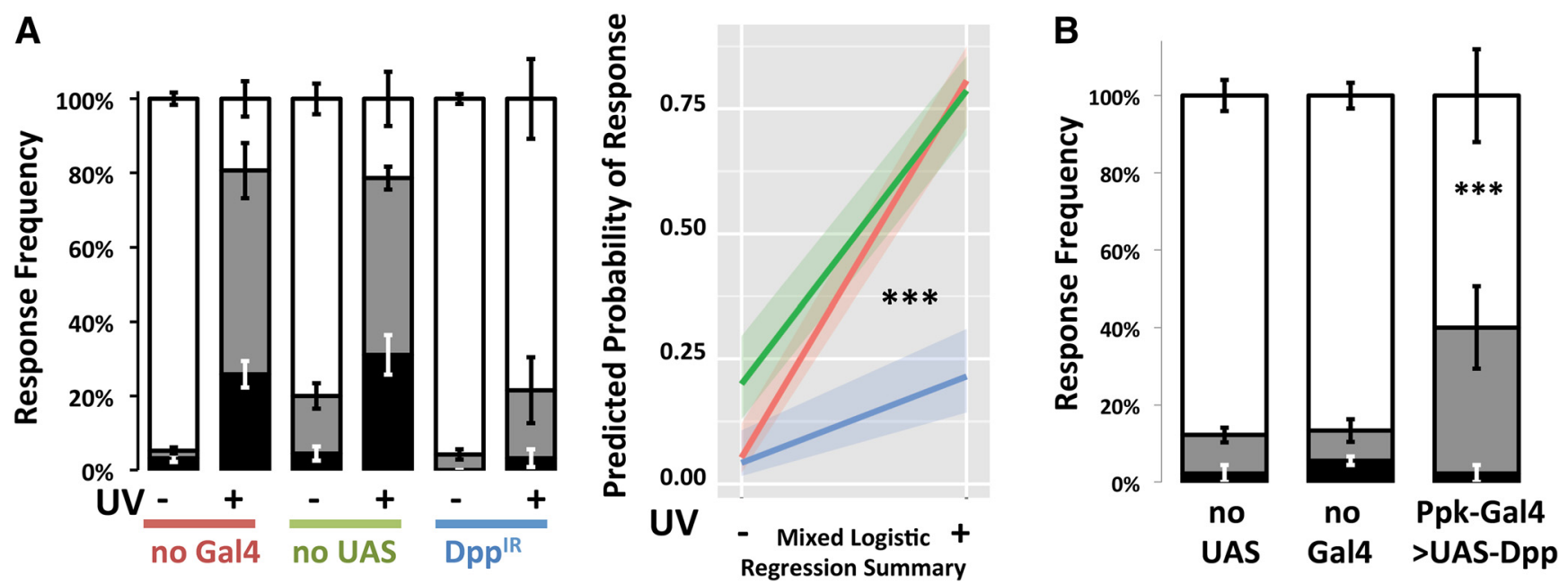

Figure 4. Manipulation of Dpp level in the primary nociceptive neurons affects production of allodynia. A, Knockdown of Dpp using a Ppk1.9-Gal4 $>$ UAS-IR RNAi genotype resulted in a failure to produce allodynia, compared with control genotypes. Following mock treatment $(-)$ or UV-injury $(+)$, larvae were assayed by gentle touch with a thermal probe set to $41^{\circ} \mathrm{C}$. Response latencies were recorded in seconds and categorized as follows: none ( $>20 \mathrm{~s}$, white area), slow ( $6-20 \mathrm{~s}$, gray area), and fast ( $<6 \mathrm{~s}$, black area). Whiskers indicate SEM of at least three groups of larvae; total $n=90-117 . B$, Overexpression of Dpp in Ppk1.9-Gal4>UAS-Dpp larvae caused hypersensitivity in the absence of UV injury ( $p<0.001)$. The probability of a nocifensive response at $41^{\circ} \mathrm{C}$ was calculated for each group by MLR analysis and was seen to increase significantly compared with control genotypes no-Gal4 ( $\left.w^{1118}>U A S-I R\right)$ and no-UAS $\left(\right.$ Ppk1.9-Gal4 $\left.>y^{7} v^{7}\right) . n=90$ for each group. ${ }^{* * *} p<0.001$.

Table 1. $p$ values corresponding to MLR analysis $^{a}$

\begin{tabular}{|c|c|c|c|c|c|}
\hline Genotype & Control & Difference & Lower & Upper & $p$ \\
\hline $\mathrm{W}^{1118}\left(\mathrm{UV}^{+}\right)$ & $\mathrm{W}^{1118}\left(\mathrm{UV}^{-}\right)$ & 0.64 & 0.51 & 0.75 & $<0.001$ \\
\hline$D p p^{I R}$ & No UAS & 0.58 & 0.42 & 0.72 & $<0.001$ \\
\hline$D p p^{I R}$ & No Gal4 & 0.6 & 0.44 & 0.74 & $<0.001$ \\
\hline$D p p^{I R-2}$ & No UAS & 0.43 & 0.26 & 0.59 & $<0.001$ \\
\hline$D p p^{I R-2}$ & No Gal4 & 0.6 & 0.44 & 0.74 & $<0.001$ \\
\hline Put $^{\text {IR }}$ & No UAS & 0.67 & 0.53 & 0.79 & $<0.001$ \\
\hline Put $^{\text {IR }}$ & No Gal4 & 0.3 & 0.14 & 0.46 & $<0.001$ \\
\hline Put ${ }^{\text {IR-2 }}$ & No UAS & 0.48 & 0.32 & 0.63 & $<0.001$ \\
\hline Put ${ }^{I R-2}$ & No Gal4 & 0.38 & 0.2 & 0.55 & $<0.001$ \\
\hline $\mathrm{TkV}^{\mathrm{IR}}$ & No UAS & 0.53 & 0.37 & 0.68 & $<0.001$ \\
\hline $\mathrm{Tkv}^{\mathrm{IR}}$ & No Gal4 & 0.43 & 0.26 & 0.6 & $<0.001$ \\
\hline$T k^{I R-2}$ & No UAS & 0.57 & 0.41 & 0.72 & $<0.001$ \\
\hline Tkv ${ }^{\text {IR-2 }}$ & No Gal4 & 0.47 & 0.3 & 0.63 & $<0.001$ \\
\hline Sax ${ }^{I R}$ & No UAS & 0.71 & 0.57 & 0.82 & $<0.001$ \\
\hline Sax ${ }^{I R}$ & No Gal4 & 0.35 & 0.2 & 0.5 & $<0.001$ \\
\hline Sax ${ }^{I R-2}$ & No UAS & 0.55 & 0.39 & 0.7 & $<0.001$ \\
\hline Sax ${ }^{I R-2}$ & No Gal4 & 0.41 & 0.23 & 0.57 & $<0.001$ \\
\hline $\operatorname{Mad}^{1 R}$ & No UAS & 0.56 & 0.41 & 0.71 & $<0.001$ \\
\hline $\operatorname{Mad}^{\mathrm{IR}}$ & No Gal4 & 0.28 & 0.11 & 0.45 & $<0.001$ \\
\hline $\operatorname{Med}^{\mathrm{IR}}$ & No UAS & 0.49 & 0.32 & 0.65 & $<0.001$ \\
\hline $\operatorname{Med}^{\mathrm{IR}}$ & No Gal4 & 0.12 & -0.06 & 0.3 & $>0.05$ \\
\hline UAS-dpp & No UAS & 0.28 & 0.12 & 0.43 & $<0.001$ \\
\hline UAS-dpp & № Gal4 & 0.27 & 0.1 & 0.43 & $<0.001$ \\
\hline
\end{tabular}

${ }^{a}$ Estimated difference in the probability of reacting to a stimulus after UV sensitization for the various treatment group pairs. The lower and upper bounds indicate the bounds to the $99 \%$ Cl about the estimated difference, and the final column indicates the $p$ value of the estimated difference in reaction probability. The differences, confidence bounds, and $p$ values were all found via parametric bootstrapping (10,000 iterations) using the MLR model fit to the data.

mean integrated density was measured as the product of the area of the region of interest and the mean gray value in the desired channel. All images were obtained with the same exposure and camera conditions to compare integrated densities.

Visualization of BMP receptor expression by GFP tagging. Because suitable antibodies to Sax and Tkv were not available, a GFP tagging approach was used (Venken et al., 2011). MiMIC lines were produced by the Gene Disruption Project, in which a GFP coding sequence was inserted intronically such that target genes produce the cognate protein translationally fused to GFP, thus making the protein directly visible via GFP fluorescence. Two MiMIC lines were selected, MI05726 and
MI08515, corresponding to Sax and Tkv, respectively. Before use in imaging, the normal function of the GFP-modified genes was confirmed by determining their ability to complement deficient alleles $\left(s a x^{5}\right.$ and $\left.t k v^{4}\right)$. GFP/deficient flies developed successfully in both cases.

Statistical analysis. To estimate the predicted probability of reacting for the different treatment groups in sensitization experiments, the response variable (reaction time) was collapsed into a binary variable and a generalized linear mixed model (with a logistic link function) was fit to the data for each pathway component using the lme4 package (version 1.1.7) (Bates et al., 2014) in R 3.1.3 (R Core Team, 2015) where larvae batch was modeled as a random effect (mixed logistic regression [MLR] analysis). To estimate the $99 \%$ CIs for the various contrasts found in Table 1, a parametric bootstrap (10,000 iterations) was performed using the corresponding models fit to the data. To test whether the differences between the postinjury reaction probabilities were significant, bootstrap CIs were constructed (at the $\alpha=0.05,0.01$, and 0.001 levels) and inverted to test the significance of various comparisons at the corresponding $\alpha$ level. In graphs depicting results of allodynia experiments, whiskers indicate SEM of at least three groups of larvae. For normal nociceptive behavior and morphometry, a Welch's $t$ test was performed. Immunoreactivity was compared using a one-way ANOVA with Tukey-Kramer Multiple Comparisons Test.

\section{Results}

To optimally assay the nociceptive behavior of Drosophila larvae, a thermal dose-response study was performed on a standard control genotype $\left(w^{1118}\right)$. Beginning at $39^{\circ} \mathrm{C}$, the temperature of the thermal probe was increased in $1^{\circ} \mathrm{C}$ increments; and at each temperature, 90 larvae were assayed for behavioral response. The response latency of each larva to its particular test temperature was recorded. From $39^{\circ} \mathrm{C}$ to $41^{\circ} \mathrm{C}$, most larvae did not respond. However, beginning at $42^{\circ} \mathrm{C}$, there was a steady increase in responsiveness with temperature, continuing to $50^{\circ} \mathrm{C}$ (Fig. 2). Because no animals responded at $41^{\circ} \mathrm{C}$ and a statistically significant number responded at $42^{\circ} \mathrm{C}$ (MLR), $41^{\circ} \mathrm{C}$ was selected as the maximum innocuous temperature at which to test for allodynia in this study.

To test for the development of thermal allodynia following injury, control flies $\left(w^{1118}\right)$ were divided into two groups: a UVirradiated group and a non-UV-irradiated group. In the non$\mathrm{UV}$-irradiated group, very few animals responded to $41^{\circ} \mathrm{C}$ stimulation, whereas a significantly greater number of animals 

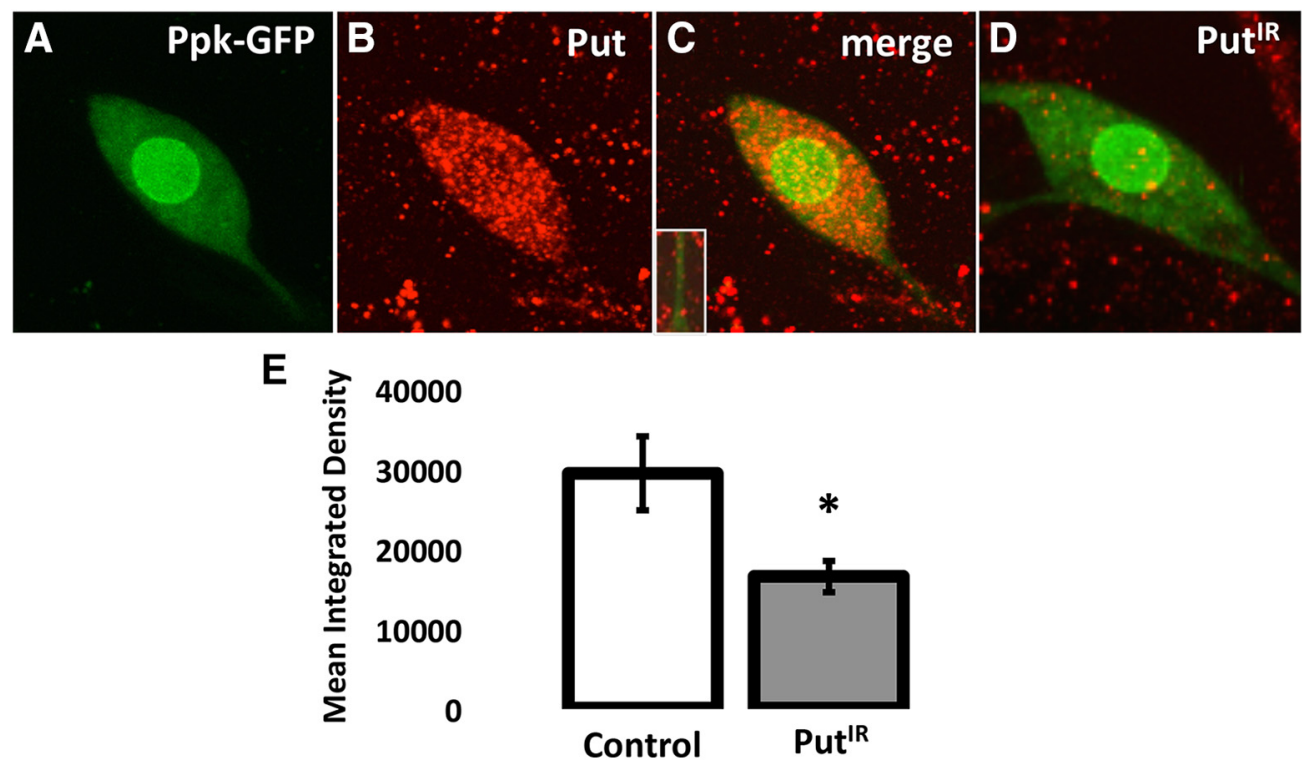

Figure 5. Localization of BMP receptor Put in nociceptive neurons. Nociceptive neurons were identified by GFP expression in larvae expressing GFP under the control of the pickpocket promoter (green; $\boldsymbol{A}, \boldsymbol{C}, \boldsymbol{D})$. Fillets were incubated with antibodies recognizing Put and fluorescently labeled secondary antibodies (red; $\boldsymbol{B}-\boldsymbol{D}$ ) and visualized by confocal microscopy. Put expression was observed in somata and major dendritic branches ( $\boldsymbol{C}$, inset) of nociceptive neurons as well as other cells. Compared with controls, the expression of Put in nociceptive neurons was significantly reduced ( $\boldsymbol{D}, \boldsymbol{E}$; $p<0.02$, Student's $t$ test) by cell-specific RNAi suppression. ${ }^{*} p=0.05-0.01$.
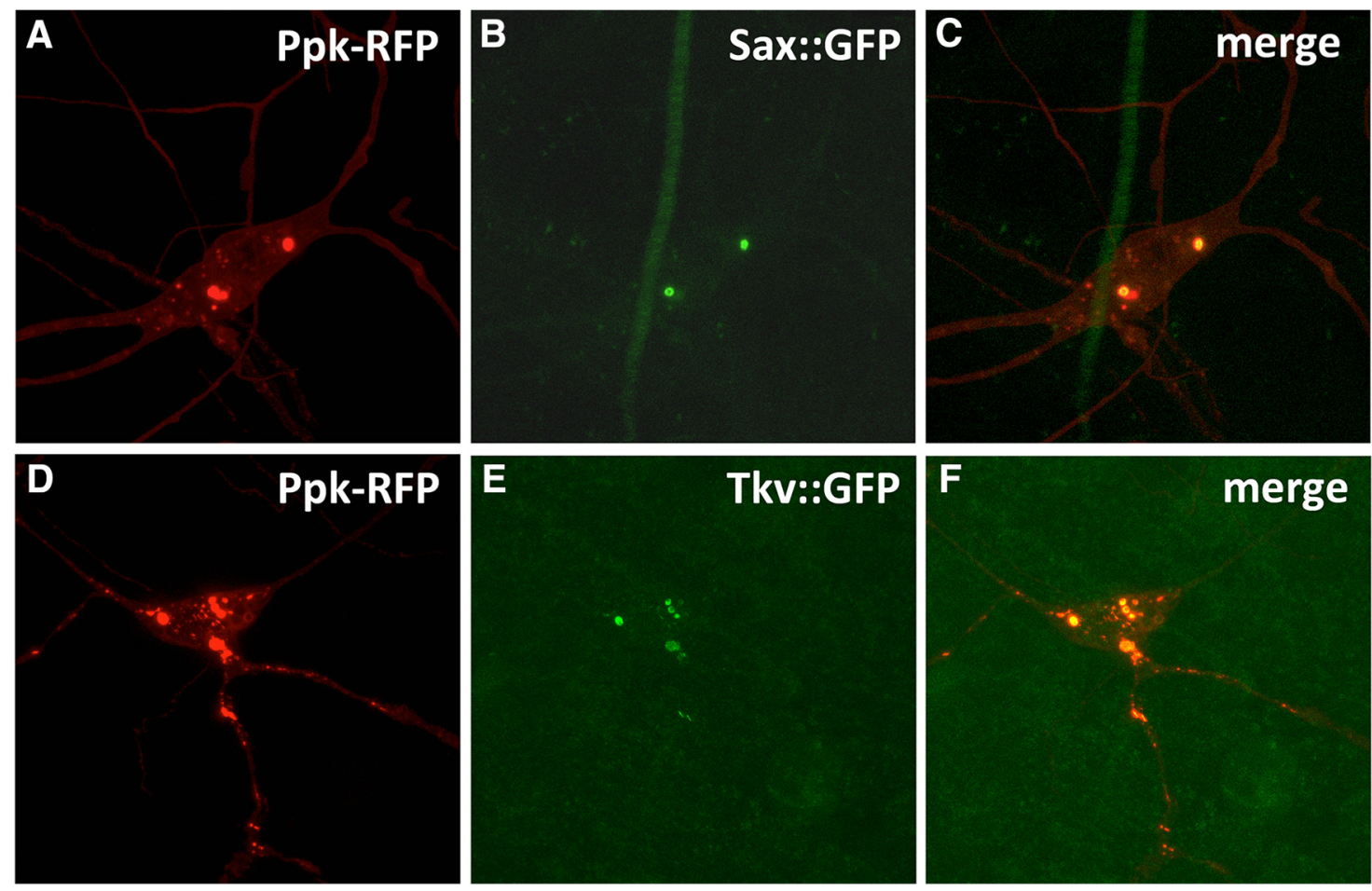

Figure 6. Localization of BMP receptors Tkv and Sax in nociceptive neurons. Tkv ( $\boldsymbol{A}-\boldsymbol{C})$ and Sax (D-F) expression in nociceptive neurons was confirmed by colocalization of GFP-tagged Sax or Tkv (green; $\boldsymbol{B}, \boldsymbol{C}, \boldsymbol{E}, \boldsymbol{F})$ and nociceptive neuron-specific expression of red fluorescent protein (red; $A, C, D, F)$. Using the MiMIC method, fluorescently tagged Sax and Tkv were observed in the somata and major dendritic branches of nociceptive neurons, as well as in other unidentified cells.

responded at this temperature after exposure to UV irradiation $(p<0.001$, MLR; Fig. $3 A)$. The possibility that UV irradiation affects the dendritic architecture of nociceptive neurons was examined in animals bearing a $P p k-G F P$ transgene that causes expression of GFP specifically in these cells. Nociceptive neurons dendritic branching and length (Fig. 3B) were measured after either UV treatment (right bars) or mock treatment (left bars).
Neurons were analyzed at $24 \mathrm{~h}$ after injury, the time of peak development of allodynia (Babcock et al., 2009). No statistically significant differences were observed between treatment groups (MLR).

Using IR transgenics to trigger RNA $i$-mediated knockdown of Dpp expression in the nociceptive neurons, we observed that suppressing the availability of the Dpp reduced the development 

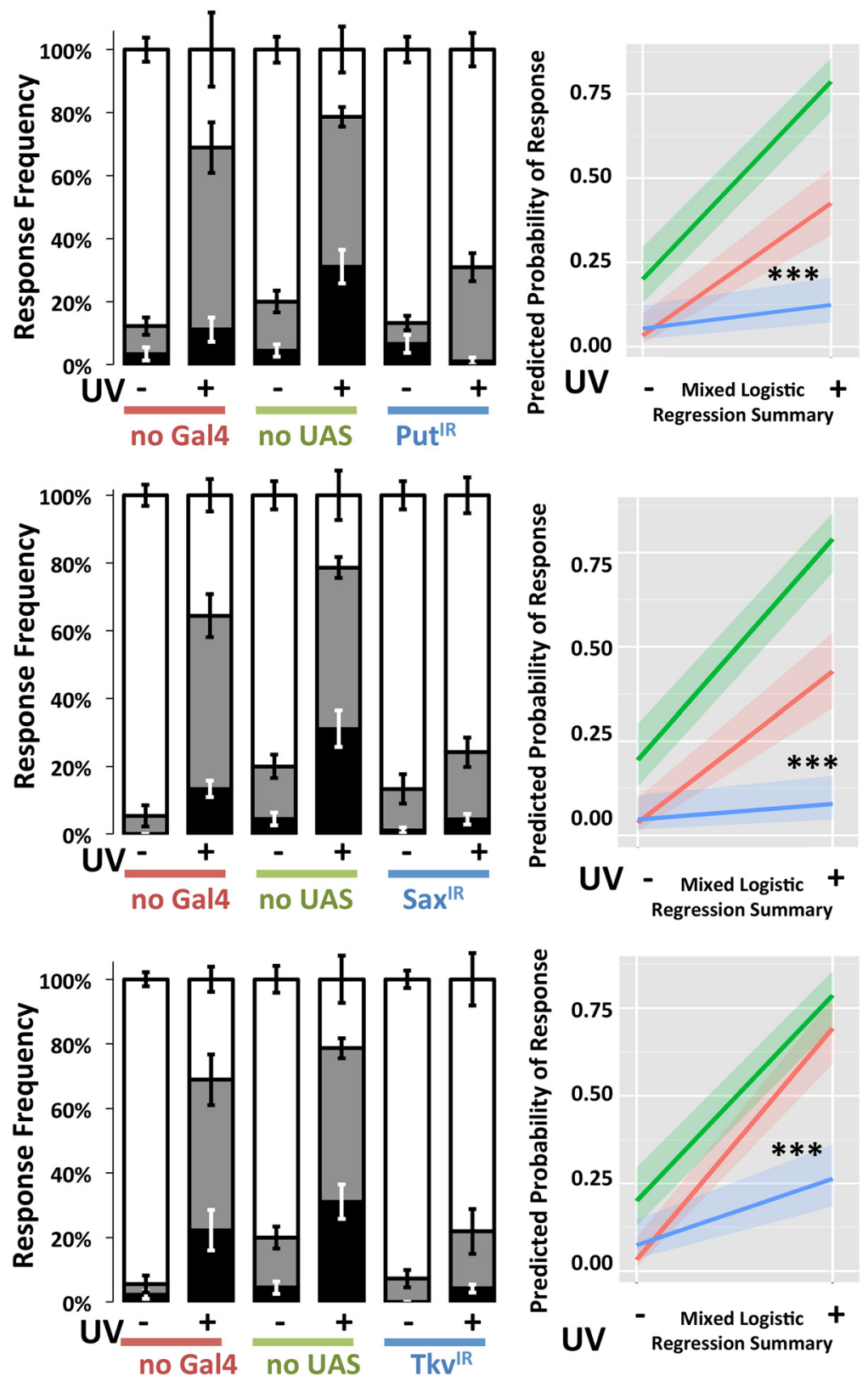

Figure 7. BMP receptors are required in nociceptive neurons for injury-induced allodynia. Ppk1.9-Gal4 $>$ UAS-IR RNAi genotypes targeting Put $(\boldsymbol{A})$, Sax $(\boldsymbol{B})$, or Tkv $(\boldsymbol{C})$ were prepared. Following mock treatment $(-)$ or UV-injury $(+)$, larvae were assayed by gentle touch with a thermal probe set to $41^{\circ} \mathrm{C}$. Response latencies were recorded in seconds and categorized as follows: none $(>20 \mathrm{~s}$, white area), slow (6-20s, gray area), and fast $(<6 \mathrm{~s}$, black area). Larvae of all three genotypes failed to produce allodynia after injury. Probability of response was compared with control genotypes no-Gal4 ( $w^{1118}>$ UAS-IR) and no-UAS (Ppk1.9Gal $\left.4>y^{7} v^{7}\right)$ by MLR analysis. Whiskers indicate SEM of at least three groups of larvae; total $n=83-103$. ${ }^{* *} p<0.001$.

of thermal allodynia. Compared with controls, the $\mathrm{Dpp}^{\mathrm{IR}}$ animals demonstrated a strong attenuation of allodynia $(p<0.001$, MLR; Fig. 4A). It was previously observed that overexpression of TNF- $\alpha$ by the epidermal cells can induce allodynia via paracrine signaling in the absence of injury (Babcock et al., 2009) as well as induce autocrine activation of $\mathrm{Hh}$ signaling (Babcock et al., 2011) and TK signaling (Im et al., 2015). In a similar experiment, UAS$D p p$ was used to drive overexpression of Dpp in the nociceptive neurons to determine whether increased Dpp availability was sufficient to induce thermal allodynia without prior injury via UV irradiation ( $p<0.001$, MLR; Fig. $4 B)$. Uninjured larvae with elevated Dpp expression showed significantly higher sensitivity to the $41^{\circ} \mathrm{C}$ probe, compared with control animals ( $p<0.001$, MLR; Fig. $4 B$ ).

Several membrane receptors have been implicated in transducing Dpp signals. These are Put (Letsou et al., 1995), Tkv (Ruberte et al., 1995), and Sax (Nellen et al., 1994; Xie et al., 1994). The various receptors for Dpp can be detected via immunohistochemistry and protein tagging in the nociceptive neurons (Figs. 5; 6). The expression of these Dpp receptors was suppressed to test for their requirement in nociceptive neurons for the formation of allodynia following UV irradiation. Significant reduction (Fig. $5 D, E$ ) in the level of Put expression was confirmed by immunocytochemistry. Expression of Sax and Tkv in the somata and dendrites of nociceptive neurons and other cells was observed using a GFP tagging approach (Fig. 6). Very faint Sax expression, but not Tkv expression, was observed in axon terminals (data not shown). Injury did not alter the expression pattern of either Tkv or Sax (data not shown). Larvae in which each receptor, Put (Fig. 7A), Sax (Fig. 7B), or Tkv (Fig. $7 C$ ), was individually suppressed showed strong attenuation in the formation of allodynia ( $p<0.001$, MLR). Similar reductions in sensitization were observed in animals in which Dpp, Put, Tkv, and Sax were individually suppressed using RNAi lines independent from and nonoverlapping with those shown above, indicating that the effects observed are not due to offtarget suppression (data not shown).

To test for the requirement of canonical SMAD signaling downstream of these receptors (see Fig. 1), the expression of Mad in nociceptive neurons was suppressed through Ppk1.9-Gal4-mediated expression of a UAS-RNAi transgene targeting Mad, Mad ${ }^{\mathrm{IR}}$. Larvae with suppressed Mad demonstrated significantly less injury-induced sensitization compared with relevant controls $(p<0.001$, MLR; Fig. 8A). When the co-SMAD Med was suppressed, the larvae again demonstrated significantly less injury-induced sensitization $(p<0.001$, MLR; Fig. $8 B)$ compared with the no UAS control group

$\left(\right.$ Ppk1.9-Gal4> $\left.>y^{l} v^{l}\right)$. Mad activation by the Type I BMP receptors Tkv and Sax following UV injury was quantified by immunohistochemistry using an antibody specific to the phosphorylated form of Mad (anti-pSmad1/5/8) at various times after UV damage. Eight hours after injury, predominantly nuclear basal phospho-Mad (p-Mad) immunoreactivity was increased by $125.53 \%(p<0.001$, Tukey-Kramer Multiple Comparisons Test) and returned to normal levels by $24 \mathrm{~h}$ (Fig. 9).

To confirm that larvae in which BMP components were suppressed maintained their ability to respond to noxious stimulation, nociceptive responses of uninjured animals to a suprathreshold temperature $\left(45^{\circ} \mathrm{C}\right)$ were examined. The behavioral 
response latencies to this noxious thermal stimulus for all of the knockdown groups were not significantly different from both control groups (Fig. 10; Welch's $t$ test).

The suppression of Dpp or the BMP receptors Tkv and Sax in nociceptive neurons did not result in any changes in dendritic length or in total dendritic branches. Suppression of Put, Mad, or Med resulted in small increases in dendritic branching (Put, $p<0.007$; Mad, $p<0.022$; and Med, $p<0.04$, Welch's $t$ test), but no significant changes to dendritic length were observed (Fig. 11). Larvae overexpressing Dpp in the nociceptive neurons showed a statistically significant reduction in length $(p<0.04$, Welch's $t$ test) and dendritic branching $(p<0.025$, Welch's $t$ test).

\section{Discussion}

This study demonstrates a requirement for the BMP signaling pathway, particularly the components immediately downstream of Dpp (see Fig. 1), for the formation of thermal allodynia in Drosophila larvae in response to UV-induced tissue injury. BMPs are known to play important roles in developmental contexts, including Drosophila imaginal discs (Affolter and Basler, 2007) and bone formation in vertebrates (Wisotzkey et al., 1998). These roles include control of cell proliferation and specification of cell fate. The BMP pathway has been implicated in neural and synaptic development in vertebrates and invertebrates (Guha et al., 2004; James et al., 2014). BMP functions are well conserved across species, and particularly strong orthology exists between mammalian BMP 2/4 and invertebrate Dpp (Padgett et al., 1993; Sampath et al., 1993). This report describes a novel role for BMP signaling in nociceptive sensitization.

In previous studies performed in Drosophila and other animals, the Dpp signaling pathway has been well elucidated (Liu and Niswander, 2005; Affolter and Basler, 2007). Exogenous Dpp has been shown to specify cell fates, for example, in the developing wing, by binding its Type II receptor Put. Put then activates either of two Type I receptors, Tkv (ortholog of mammalian ALK3/6) or Sax (ortholog of mammalian ALK1/2). In many mammalian contexts, BMPs act as morphogens that trigger the specification of bone (Urist, 1965). With regard to roles in sensory processes, BMPs (Ai et al., 1999) and another member of the TGF- $\beta$ superfamily, activin (Xu et al., 2007), are known to increase expression of calcitonin gene-related peptide in sensory neurons. TGF- $\beta$ is known to regulate opioid transmitter synthesis (Kamphuis et al., 1997), and mice deficient in a TGF- $\beta$ signaling inhibitor, BAMBI, are hyposensitive to noxious stimuli (Tramullas et al., 2010).

Previous studies have shown that upon cutaneous tissue injury by UV exposure and subsequent TNF $\alpha$ signaling by the apoptotic epidermal cells (Babcock et al., 2009), Hh is released from
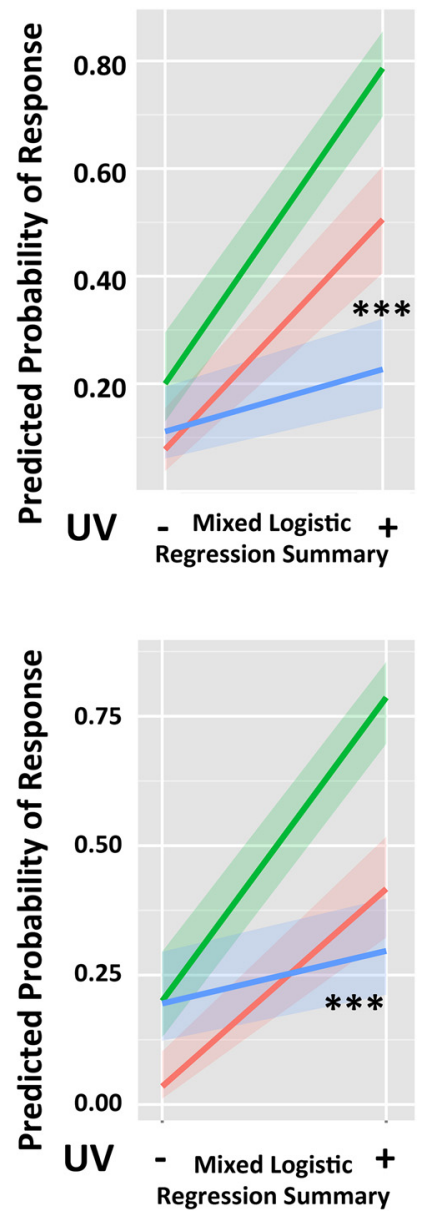

Figure 8. Canonical intracellular transducers are required in nociceptive neurons for injury-induced allodynia. Knockdown of follows: none ( $>20 \mathrm{~s}$, white area), slow ( $6-20 \mathrm{~s}$, gray area), and fast ( $<6 \mathrm{~s}$, black area). Whiskers indicate SEM of at least three groups of larvae; total $n=82-103$. Allodynia in larvae with suppressed Med was significantly different from one of its con Mad suppression resulted in allodynia significantly reduced compared with both controls. ${ }^{* * *} p<0.001$.

nociceptive neurons in response to TK signaling from the CNS (Im et al., 2015). Hh activation of its receptor Patched, located on nociceptive neurons, produces allodynia (Babcock et al., 2011). The observation that allodynia requires Dpp is consistent with previous data demonstrating Hh upregulation of Dpp expression in developmental contexts (Hooper and Scott, 2005). This study establishes that Dpp is necessary for injury-induced sensitization of nociceptive neurons. Furthermore, experimental overexpression of Dpp in nociceptive neurons produces allodynia in the absence of injury, supporting the conclusion that Dpp is sufficient for the formation of allodynia. Last, knockdown of Dpp does not alter normal nociceptive function, indicating that Dpp signaling is specific for nociceptive neuron sensitization.

The requirement of BMP components (see Fig. 1) in nociceptive neurons to produce sensitization was investigated by suppressing their expression in these neurons using Ppk1.9-Gal4 to drive expression of gene-specific IR RNAi constructs, which trigger the destruction of the matching endogenous mRNA, specifically in the nociceptive neurons. Results indicate that Dpp, its Type II primary receptor Put, and the Type I receptors Tkv and Sax are all necessary in the nociceptive neuron for the formation of allodynia. This suggests, but does not confirm, the possibility that the Dpp nociceptive sensitization pathway involves an auto- 

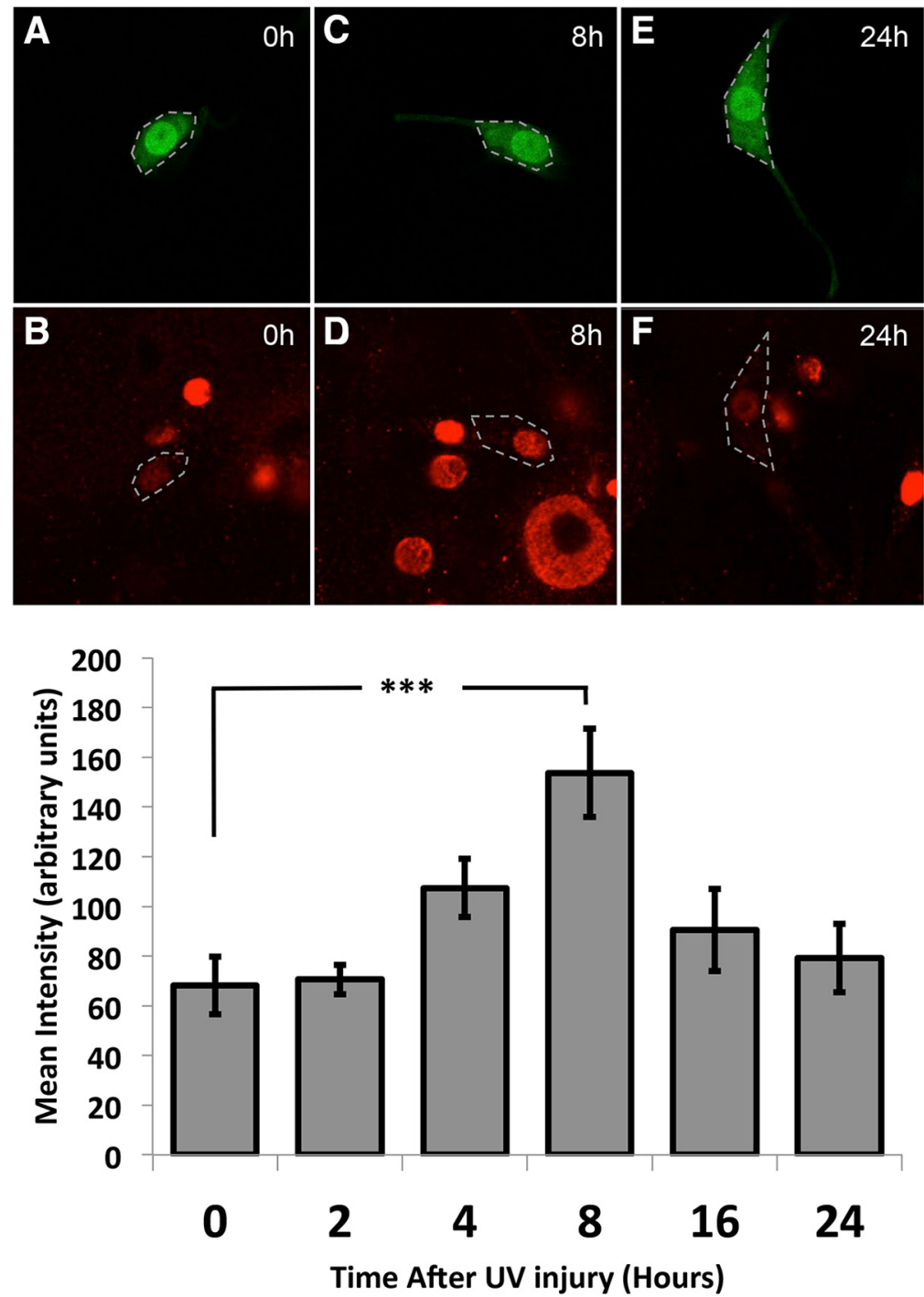

Figure 9. Mad phosphorylation in nociceptive neurons increases after injury. GFP expression indicates nociceptive neurons (green; $\boldsymbol{A}, \boldsymbol{C}, \boldsymbol{E}$ ) and anti-phospho-Mad immunoreactivity (red; $\boldsymbol{B}, \boldsymbol{D}, \boldsymbol{F}$ ). Cell bodies of the nociceptive neurons are shown outlined in white. $\boldsymbol{A}, \boldsymbol{B}$, Representative images of staining immediately following UV injury. $\boldsymbol{C}, \boldsymbol{D}$, Representative images of staining $8 \mathrm{~h}$ after UV injury. $\boldsymbol{E}, \boldsymbol{F}$, Representative images of staining $24 \mathrm{~h}$ following UV injury, at the time of peak allodynia. $\boldsymbol{G}$, Average calculated mean intensities of phospho-Mad signaling in the nuclei of the nociceptive neurons at 2, 4,8,16, and $24 \mathrm{~h}$ after injury. $n>9$ for each group. Significant increase in anti-phospho-Mad immunofluorescence detected at $8 \mathrm{~h}:{ }^{* * *} p<0.001$ (one-way ANOVA and Tukey-Kramer Multiple Comparisons Test)

crine signaling strategy. Because suppression of either Dpp or its receptors specifically in the nociceptive neurons produces a blockade of injury-induced thermal allodynia, it may be that Dpp is produced in the nociceptive neuron following epithelial tissue damage, then is released and interacts with that same nociceptive neuron's Dpp receptors. BMPs are known to signal through autocrine mechanisms at the neuromuscular junction (James et al., 2014), but a role for autocrine BMP signaling in sensory neurons has not been previously reported.

The effects of BMP signaling on nociception are specific to nociceptive neuron sensitization, as supported by the finding that manipulation of receptor expression via RNAi did not alter behavioral responses to noxious thermal stimulation. To demonstrate that the results of manipulating BMP signaling are specific to the sensitization pathway and not a general loss of nociceptive functioning in these neurons, uninjured RNAi-suppressed larvae were tested at the normally noxious $45^{\circ} \mathrm{C}$ (Babcock et al., 2009, 2011). No changes to normal nociception were observed.
The necessity of both Type I receptors, Sax and Tkv, for the formation of allodynia suggests that Dpp binds as a dimer, as has been demonstrated in prior studies of TGF- $\beta$ members (Daopin et al., 1992), to trigger the allodynia-producing pathway in this cell. Both Type I receptors are independently necessary; thus, both must be activated to produce allodynia. Perhaps this mechanism of sensitization suggests a reason why congenital Type I BMP receptor ALK2 hyperactivation in human patients suffering from fibrodysplasia ossificans progressiva increases the incidence of neuropathic pain and allodynia (Kitterman et al., 2012).

The Type I BMP receptors are known to activate the canonical SMAD signaling protein Mad (Raftery et al., 1995) through phosphorylation to form p-Mad (see Fig. 1). Then p-Mad forms a complex with the co-SMAD Med, homolog of human SMAD4 (Wisotzkey et al., 1998), which translocates to the nucleus to regulate gene expression. Upon suppression of Mad and Med, the formation of allodynia was significantly attenuated, demonstrating that the canonical pathway is required for the manifestation of allodynia. Furthermore, immunolocalization of $\mathrm{p}$-Mad, following UV-induced tissue damage, revealed that nuclear $\mathrm{p}$-Mad levels were nominally elevated by $4 \mathrm{~h}$ after injury, reached a statistically significant peak $8 \mathrm{~h}$ after injury, and returned to baseline at $24 \mathrm{~h}$ following injury. This time course is consistent with the onset of hypersensitivity (Babcock et al., 2009).

Morphometric analysis was performed to determine whether the induction of allodynia following UV-mediated tissue damage was accompanied by changes to the dendritic architecture of the nociceptive neurons. No significant morphological differences between the neurons of UVirradiated larvae and those of unirradiated controls were found, indicating that the observed hypersensitivity following UV damage is a result of intrinsic mechanisms of sensitivity, rather than changes in dendritic morphology. This also suggests that the morphological changes observed in some RNAi manipulations may be the result of a developmental effect of BMP perturbation.

In some experimental groups, there were some differences in dendritic morphology that may indicate a separate role for BMP signaling in these peripheral tissues (Fig. 11). First, Put knockdown resulted in a significant increase in the amount of dendritic branching. The direction of this effect is opposite from what might be expected given the observed failure of UV injury to produce allodynia in this manipulated animal. Similarly, when Dpp was upregulated in the nociceptive neurons, a decrease in both dendritic branching and overall dendritic length of these nociceptive neurons was observed. The direction of these effects is also in opposition to the formation of injury-independent allodynia. These inconsistencies between the results of a genetic 


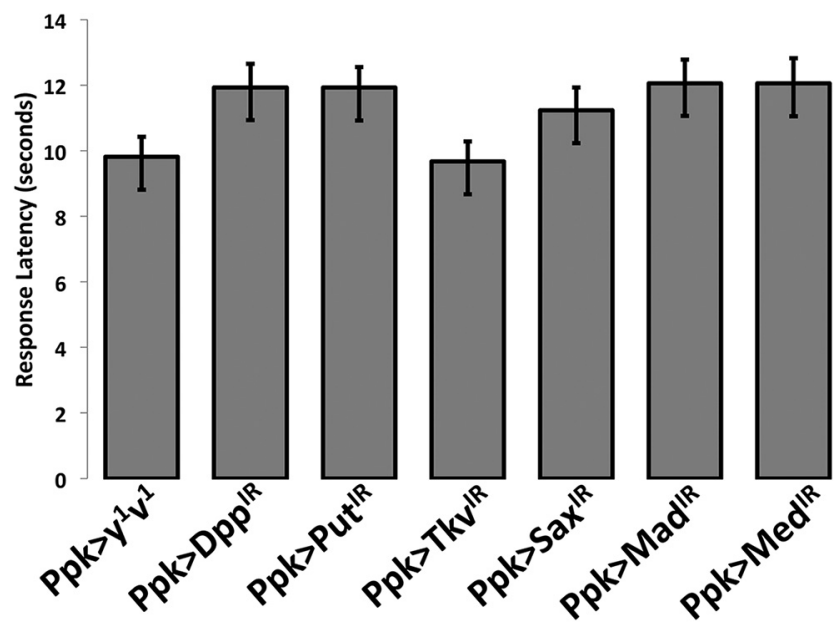

Figure 10. Nociception of larvae of RNAi and control genotypes is similar at normally noxious temperature of $45^{\circ} \mathrm{C}$. Normal nociceptive responses were tested to determine the normal nociception behavior of uninjured larvae. These data show that uninjured animals bearing IR RNAi genotypes reducing expression of BMP components are as capable of responding to normally noxious thermal stimuli as are the controls. Probe temperature was set to $45^{\circ} \mathrm{C} . n=90$ for all groups. In no case did an RNAi genotype show a significant difference from both no-UAS (Ppk1.9-Gal4 $\left.>y^{1} v^{7}\right)$ controls (Welch's $t$ test).

manipulation on dendritic morphology and allodynia suggest that some factor other than the degree of dendritic arborization connects BMP signaling to the development of allodynia. The literature describing the role of BMP signaling in plasticity of the neuromuscular junction (James and Broihier, 2011; James et al., 2014) suggests that the effect of BMP signaling on injury-induced allodynia could be to produce changes in synaptic strength at the central terminals of the nociceptive neurons in the ventral nerve cord, where connections are made with the first-order interneurons of the central nociceptive circuitry (Ohyama et al., 2015).

It has been reported that BMP released from epithelial tissues acts to control the degree of sensory neuron innervation through density of terminal fields and total number of neurons in the DRGs of mice (Guha et al., 2004). Inhibition of dendritic growth by epithelially derived Dpp could explain why the RNAi manipulations of BMP receptor Put resulted in an increase in total dendritic branching. This model is consistent with our observation that, in animals with Dpp suppressed in nociceptive neurons, normal dendritic morphology was observed. In this case, Dpp knockdown in the nociceptive neurons would not be expected to have any effect on the pool of Dpp that might be released from the epithelial cells; however, the nociceptive neurons of such animals still have intact receptor machinery to perceive and transduce the epithelial-derived Dpp signal, thus resulting in normal dendritic architecture. On the other hand, upregulating Dpp in the nociceptive neuron would lead to an increase in Dpp signaling around that neuron and would increase the inhibitory signal, cuing a decrease in dendritic growth, as observed.

In conclusion, this report demonstrates that Dpp expression in the nociceptive neuron is both necessary and sufficient for the production of thermal allodynia. Dpp signals to the primary Type II receptor Put, in turn activating Type I receptors Tkv and Sax, which then activate the canonical signaling pathway by phosphorylating Mad to ultimately produce allodynia (Fig. 1). Suppression of these components has no observed effect on the normal nociceptive functioning of these cells and only minor effects on their dendritic morphology. Because of the high degree of conservation of the BMP system between vertebrates and invertebrates, the pharmacological

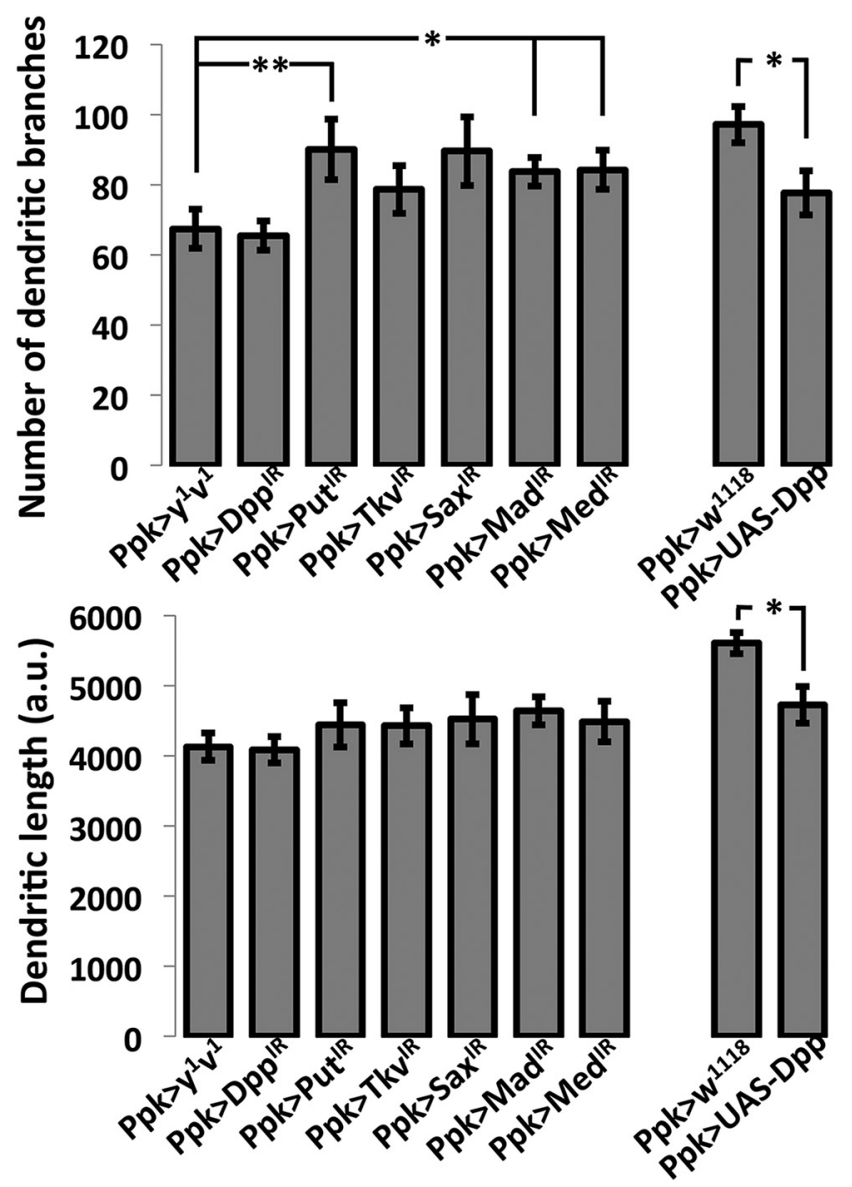

Figure 11. Morphology of nociceptive neuron dendritic fields of larvae in which BMP components were manipulated compared with that of normal larvae. Morphological parameters measured were the total number of dendritic branches $(\boldsymbol{A})$ and total dendritic length $(\boldsymbol{B})$. Larvae in which Dpp was suppressed in nociceptive neurons by IR-triggered RNAi exhibited no significant differences in dendritic branching compared with control genotype Ppk1.9-Gal4 $>y^{1} v^{1}$, nor did larvae in which Tkv or Sax were similarly suppressed. Nociceptive neuron branching was increased in larvae in which Put $(p<0.007)$, Mad $(p<0.022)$, or Med $(p<0.04)$ was suppressed $(\boldsymbol{A})$, but no RNAi manipulation significantly altered overall dendritic length $(\boldsymbol{B})$. Overexpression of Dpp in the nociceptive neurons $(\boldsymbol{A}, \boldsymbol{B}$, rightmost bar) significantly decreased dendritic branching $(p<0.025)$ and dendritic length $(p<0.04)$, compared with control genotype Ppk1.9-Gal4 $>w^{1118}$. Skeletons were constructed in Fiji, and total dendritic length and total number of branches were calculated. Data were analyzed using Welch's $t$ test. $n=$ $18-30$. ${ }^{*} p=0.05-0.01$. ${ }^{* *} p<0.01-0.001$.

manipulation of BMP pathways might offer an effective avenue for the treatment of chronic pain in humans.

\section{References}

Adams CM, Anderson MG, Motto DG, Price MP, Johnson WA, Welsh MJ (1998) Ripped pocket and pickpocket, novel Drosophila DEG/ENaC subunits expressed in early development and in mechanosensory neurons. J Cell Biol 140:143-152. CrossRef Medline

Affolter M, Basler K (2007) The Decapentaplegic morphogen gradient: from pattern formation to growth regulation. Nat Rev Genet 8:663-674. CrossRef Medline

Ai X, Cappuzzello J, Hall AK (1999) Activin and bone morphogenetic proteins induce calcitonin gene-related peptide in embryonic sensory neurons in vitro. Mol Cell Neurosci 14:506-518. CrossRef Medline

Ainsley JA, Pettus JM, Bosenko D, Gerstein CE, Zinkevich N, Anderson MG, Adams CM, Welsh MJ, Johnson WA (2003) Enhanced locomotion caused by loss of the Drosophila DEG/ENaC protein Pickpocket1. Curr Biol 13:1557-1563. CrossRef Medline

Babcock DT, Landry C, Galko MJ (2009) Cytokine signaling mediates UV- 
induced nociceptive sensitization in Drosophila larvae. Curr Biol 19:799806. CrossRef Medline

Babcock DT, Shi S, Jo J, Shaw M, Gutstein HB, Galko MJ (2011) Hedgehog signaling regulates nociceptive sensitization. Curr Biol 21:1525-1533. CrossRef Medline

Bates D, Maechler M, Bolker B, WalkerS (2014) lme4: linear mixedeffects models using Eigen and S4. R package version 1.0-6. https://cran.r-project.org/web/packages/lme4/index.html.

Brenner S (1974) The genetics of Caenorhabditis elegans. Genetics 77:71-94. Medline

Daopin S, Piez KA, Ogawa Y, Davies DR (1992) Crystal structure of transforming growth factor- $\beta 2$ : an unusual fold for the superfamily. Science 257:369-373. CrossRef Medline

Gaskin DJ, Richard P (2012) The economic costs of pain in the United States. J Pain 13:715-724. CrossRef Medline

Grueber WB, Jan LY, Jan YN (2002) Tiling of the Drosophila epidermis by multidendritic sensory neurons. Development 129:2867-2878. Medline

Guha U, Gomes WA, Samanta J, Gupta M, Rice FL, Kessler JA (2004) Target-derived BMP signaling limits sensory neuron number and the extent of peripheral innervation in vivo. Development 131:1175-1186. CrossRef Medline

Hooper JE, Scott MP (2005) Communicating with Hedgehogs. Nat Rev Mol Cell Biol 6:306-317. CrossRef Medline

Im SH, Takle K, Jo J, Babcock DT, Ma Z, Xiang Y, Galko MJ (2015) Tachykinin acts upstream of hedgehog signaling during nociceptive sensitization in Drosophila. eLife 4:e10735. CrossRef Medline

Iyer SC, Ramachandran Iyer EP, Meduri R, Rubaharan M, Kuntimaddi A, Karamsetty M, Cox DN (2013) Cut, via CrebA, transcriptionally regulates the COPII secretory pathway to direct dendrite development in Drosophila. J Cell Sci 126:4732-4745. CrossRef Medline

James RE, Broihier HT (2011) Crimpy inhibits the BMP homolog Gbb in motoneurons to enable proper growth control at the Drosophila neuromuscular junction. Development 138:3273-3286. CrossRef Medline

James RE, Hoover KM, Bulgari D, McLaughlin CN, Wilson CG, Wharton KA, Levitan ES, Broihier HT (2014) Crimpy enables discrimination of presynaptic and postsynaptic pools of a BMP at the Drosophila neuromuscular Junction. Dev Cell 31:586-598. CrossRef Medline

Jo J, Im SH, Babcock DT, Iyer SC, Gunawan F, Cox DN, Galko MJ (2017) Drosophila caspase activity is required independently of apoptosis to produce active TNF/Eiger during nociceptive sensitization. Cell Death Dis 8:e2786. CrossRef Medline

Jones CM, Lyons KM, Hogan BL (1991) Involvement of Bone Morphogenetic Protein-4 (BMP-4) and Vgr-1 in morphogenesis and neurogenesis in the mouse. Development 111:531-542. Medline

Kamphuis S, Kavelaars A, Brooimans R, Kuis W, Zegers BJ, Heijnen CJ (1997) T helper 2 cytokines induce preproenkephalin mRNA expression and proenkephalin A in human peripheral blood mononuclear cells. J Neuroimmunol 79:91-99. CrossRef Medline

Kang K, Panzano VC, Chang EC, Ni L, Dainis AM, Jenkins AM, Regna K, Muskavitch MA, Garrity PA (2012) Modulation of TRPA1 thermal sensitivity enables sensory discrimination in Drosophila. Nature 481:76-80. CrossRef Medline

Kim SE, Coste B, Chadha A, Cook B, Patapoutian A (2012) The role of Drosophila Piezo in mechanical nociception. Nature 483:209-212. CrossRef Medline

Kitterman JA, Strober JB, Kan L, Rocke DM, Cali A, Peeper J, Snow J, Delai PL, Morhart R, Pignolo RJ, Shore EM, Kaplan FS (2012) Neurological symptoms in individuals with fibrodysplasia ossificans progressiva. J Neurol 259:2636-2643. CrossRef Medline

Letsou A, Arora K, Wrana JL, Simin K, Twombly V, Jamal J, StaehlingHampton K, Hoffmann FM, Gelbart WM, Massagué J, O’Connor MB (1995) Drosophila Dpp signaling is mediated by the punt gene product: a dual ligand-binding Type II receptor of the TGF beta receptor family. Cell 80:899-908. CrossRef Medline

Lin HY, Wang XF, Ng-Eaton E, Weinberg RA, Lodish HF (1992) Expression cloning of the TGF-beta Type II receptor, a functional transmembrane serine/threonine kinase. Cell 68:775-785. CrossRef Medline

Liu A, Niswander LA (2005) Bone morphogenetic protein signalling and vertebrate nervous system development. Nat Rev Neurosci 6:945-954. CrossRef Medline

Massagué J, Like B (1985) Cellular receptors for type beta transforming growth factor: ligand binding and affinity labeling in human and rodent cell lines. J Biol Chem 260:2636-2645. Medline

Neely GG, Keene AC, Duchek P, Chang EC, Wang QP, Aksoy YA, Rosenzweig M, Costigan M, Woolf CJ, Garrity PA, Penninger JM (2011) TrpA1 regulates thermal nociception in Drosophila. PLoS One 6:e24343. CrossRef Medline

Nellen D, Affolter M, Basler K (1994) Receptor serine/threonine kinases implicated in the control of Drosophila body pattern by decapentaplegic. Cell 78:225-237. CrossRef Medline

Newfeld SJ, Mehra A, Singer MA, Wrana JL, Attisano L, Gelbart WM (1997) Mothers against Dpp participates in a DDP/TGF-beta responsive serine-threonine kinase signal transduction cascade. Development 124:3167-3176. Medline

Ohyama T, Schneider-Mizell CM, Fetter RD, Aleman JV, Franconville R, Rivera-Alba M, Mensh BD, Branson KM, Simpson JH, Truman JW, Cardona A, Zlatic M (2015) A multilevel multimodal circuit enhances action selection in Drosophila. Nature 520:633-639. CrossRef Medline

Ozkaynak E, Rueger DC, Drier EA, Corbett C, Ridge RJ, Sampath TK, Oppermann H (1990) OP-1 cDNA encodes an osteogenic protein in the TGF-beta family. EMBO J 9:2085-2093. Medline

Padgett RW, Wozney JM, Gelbart WM (1993) Human BMP sequences can confer normal dorsal-ventral patterning in the Drosophila embryo. Proc Natl Acad Sci U S A 90:2905-2909. CrossRef Medline

Pandey UB, Nichols CD (2011) Human disease models in Drosophila melanogaster and the role of the fly in therapeutic drug discovery. Pharmacol Rev 63:411-436. CrossRef Medline

R Core Team (2015) R: a language and environment for statistical computing. R Foundation for Statistical Computing, Vienna. http://www.R-project.org/.

Raftery LA, Twombly V, Wharton K, Gelbart WM (1995) Genetic screens to identify elements of the Decapentaplegic signaling pathway in Drosophila. Genetics 139:241-254. Medline

Reiter LT, Potocki L, Chien S, Gribskov M, Bier E (2001) A systematic analysis of human disease-associated gene sequences In Drosophila melanogaster. Genome Res 11:1114-1125. CrossRef Medline

Ruberte E, Marty T, Nellen D, Affolter M, Basler K (1995) An absolute requirement for both the Type II and Type I receptors, Punt and Thick Veins, for Dpp signaling in vivo. Cell 80:889-897. CrossRef Medline

Sampath TK, Rashka KE, Doctor JS, Tucker RF, Hoffmann FM (1993) Drosophila transforming growth factor $\beta$ superfamily proteins induce endochondral none formation in mammals. Proc Natl Acad Sci U S A 90: 6004-6008. CrossRef Medline

Sekelsky JJ, Newfeld SJ, Raftery LA, Chartoff EH, Gelbart WM (1995) Genetic characterization and cloning of mothers against Dpp, a gene required for Decapentaplegic function in Drosophila melanogaster. Genetics 139:1347-1358. Medline

Tracey WD Jr, Wilson RI, Laurent G, Benzer S (2003) painless, a Drosophila gene essential for nociception. Cell 113:261-273. CrossRef Medline

Tramullas M, Lantero A, Díaz A, Morchón N, Merino D, Villar A, Buscher D, Merino R, Hurlé JM, Izpisúa-Belmonte JC, Hurlé MA (2010) BAMBI (bone morphogenetic protein and activin membrane-bound inhibitor) reveals the involvement of the transforming growth factor-beta family in pain modulation. J Neurosci 30:1502-1511. CrossRef Medline

Urist MR (1965) Bone: formation by autoinduction. Science 150:893-899. CrossRef Medline

Venken KJ, Schulze KL, Haelterman NA, Pan H, He Y, Evans-Holm M, Carlson JW, Levis RW, Spradling AC, Hoskins RA, Bellen HJ (2011) MiMIC: a highly versatile transposon insertion resource of engineering Drosophila melanogaster genes. Nat Methods 8:737-743. CrossRef Medline

Wangler MF, Yamamoto S, Bellen HJ (2015) Fruit flies in biomedical research. Genetics 199:639-653. CrossRef Medline

Ward EJ, Berg CA (2005) Juxtaposition between two cell types is necessary for dorsal appendage tube formation. Mech Dev 122:241-255. CrossRef Medline

Wisotzkey RG, Mehra A, Sutherland DJ, Dobens LL, Liu X, Dohrmann C, Attisano L, Raftery LA (1998) Medea is a Drosophila Smad4 homolog that is differentially required to potentiate DPP responses. Development 125:1433-1445. Medline

Xie T, Finelli AL, Padgett RW (1994) The Drosophila Saxophone gene: a serine-threonine kinase receptor of the TGF-beta superfamily. Science 263:1756-1759. CrossRef Medline

Xu P, Hall AK (2007) Activin acts with nerve growth factor to regulate calcitonin gene-related peptide mRNA in sensory neurons. Neuroscience 150:665-674. CrossRef Medline 